do ZIKV, ajudando a otimizar os recursos materiais e humanos. "Trabalhar em rede é sempre muito melhor do que trabalhar individualmente", concorda Savino, da Fiocruz. Desse modo é possível “utilizar equipamentos de médio e grande porte, que nem todos os laboratórios têm". Para ele, o modelo de trabalho em redes pode representar "uma mudança de paradigma na produção científica brasileira, favorecendo cada vez mais a cooperação em detrimento da competição".

A formação de redes tem sido incentivada pelos órgãos de apoio e fomento. Em fevereiro deste ano, a Fundação de Amparo à Pesquisa do Estado do Rio de Janeiro (Faperj) lançou edital prevendo a formação de redes cooperativas de pesquisa sobre dengue, chicungunha e zika, destinando um total de R\$ 12 milhões a serem liberados em dois anos para compras de equipamentos, custeios e de bolsas. Em março, a Fundação de Amparo à Pesquisa do Estado da Bahia (Fapesb) lançou edital semelhante, com investimentos de até $\mathrm{R} \$ 5$ milhões.

CRISE DE RECURSOS Por outro lado, as crises econômica e política têm colocado em risco a liberação de recursos. "Não tive financiamento nenhum até agora", revela Stevens Rehen, "já recebemos uma parcela de um recurso da Faperj; mas de outros dois projetos, aprovados pela Coordenação de Aperfeiçoamento de Pessoal de Nível Superior (Capes) e pela Financiadora de Estudos e Projetos (Finep), ainda não entrou nenhum recurso". Wilson Savino também relata dificuldades: "Tem bolsas que permitem compras menores. Mas os recursos de monta para equipamentos e material, esses ainda não foram liberados". Para Zanotto, ao menos em nível federal, essa situação tende a mudar. Parte do problema foi que, com a mudança de governo, muito do que havia sido acertado com o então Ministério da Ciência, Tecnologia e Inovação, hoje também das Comunicações, e a Capes tiveram que ser renegociados, atrasando a liberação das verbas e formulação de editais.

Mesmo com poucos ou até nenhum recurso novo, o trabalho dos grupos de pesquisa brasileiros para explicar aspectos fundamentais da biologia e epidemiologia do ZIKV foi expressivo. "Se você olhar a produção científica de 2015 para cá no mundo inteiro sobre zika, $27 \%$ foi feita no Brasil", observa Savino. "Isso demonstra a rapidez com que a comunidade científica brasileira respondeu a esse problema, levando a uma série de descobertas importantes", conclui.

Roberto Takata
BIODIVERSIDADE

\section{Caça a mamíferos ameaça bioma da Caatinga}

Mesmo ocupando cerca de 11\% do território brasileiro, com mais de 750 mil km², a Caatinga ainda é, hoje, um dos biomas menos conhecidos e menos protegidos do país. A escassez de chuvas, que pode perdurar por até onze meses, diminui a disponibilidade de água para plantas e animais e contribui para definir não apenas a paisagem, mas também os hábitos dos moradores. Apesar de ter sido, durante muitos anos, descrita como um ecossistema pobre em espécies e endemismos, essa visão está mudando. Estudos recentes apontam que a Caatinga apresenta uma expressiva riqueza de vertebrados silvestres quando comparada a outras regiōes semiáridas do mundo. Em relação aos vertebrados terrestres, estão catalogadas, na região, 56 espécies de anfíbios, 117 de répteis, 591 de aves e 153 de mamíferos.

Único bioma exclusivamente brasileiro, com um rico patrimônio biológico, a Caatinga sofre com as consequências do desmatamento (mais de 45\% de seu território original já foi desmatado, segundo dados do Ministério do Meio Ambiente) e de atividades de caça, fatores que, combinados, contribuem para a ex- 
-catingueiro (Mazama gouazoubira). Além de muito apreciado pelo sabor e maciez de sua carne, esse animal é, muitas vezes, alvo de competições, por ser considerado difícil de perseguir. A população está em declínio em diversas localidades, em parte devido à caça, mas também pela perda de habitat. Outras espécies muito utilizadas como alimento no semiárido brasileiro são o mocó (Kerodon rupestris) e o cateto (Pecari tacaju), também usado na medicina popular para tratar doenças como trombose, bronquite e AVC. $\mathrm{O}$ tatupeba (Euphractus sexcinctus), além de consumido como alimento, é, assim como o cateto, empregado na medicina popular. Fragmentos de cauda pele e gordura são prescritos para tratar feridas, dor de ouvido, asma, dor de garganta, pneumonia, sinusite, surdez, garganta grossa ou para desviar a inveja.

ASPECTOS CULtURAIS Para Alves, em uma perspectiva ecológica e conservacionista, a redução da pressão de caça representaria o ideal de conservação e estratégia de manejo da fauna. Todavia, essa redução não é viável na região, uma vez que a caça de animais silvestres está indissociavelmente ligada a fatores socioeconômicos. "Ignorar as motivações que levam as pessoas a usarem os produtos da fauna silvestre implica impor medidas de controle que não funcionam por uma série de fatores. A prova disso é que a caça é disseminada na região, e em todo Brasil, apesar de a legislação proibir. Por ser um tema complexo, é uma atividade que deve ser entendida em suas diferentes nuances para que se possa pensar em estratégias que busquem a conservação das espécies, mas também a manutenção das pessoas que se utilizam desse recurso como fonte de subsistência. Os produtos animais são usados para diferentes fins. No caso do uso alimentar, e quando as comunidades locais dependem da atividade para subsistência, é recomendável que sejam planejadas formas de exploração sustentável do recurso. Nesse âmbito, a própria legislação permite que as comunidades tradicionais possam caçar para sua subsistência. Na maior parte da Caatinga, no entanto, a caça está associada ao aspecto cultural. Muitas vezes o indivíduo inicia as atividades cinegéticas ainda na infância, influenciado por parentes. As pessoas envolvidas consideram a prática como um esporte e é comum que se reúnam com amigos nos fins de semana em clima de descontração e aventura", esclarece.

Diante dessas realidades distintas, Alves aponta a necessidade de implementar medidas destinadas a garantir a sustentabilidade da caça regional e minimizar os impactos sobre as populações animais. Como ações que poderiam contribuir para equilibrar a situação, os pesquisadores destacam o desenvolvimento de programas educacionais de manejo da vida selvagem (no caso da caça de subsistência), com fortes componentes de legislação ambiental e sua aplicação efetiva (no caso de caça para entretenimento); a criação de canais de comunicação entre instituições acadêmicas e governamentais e os envolvidos na caça e a intensificação das ações de fiscalização da caça para entretenimento. Além dessas medidas, o pesquisador afirma que é preciso considerar também o comércio ilegal de animais silvestres, que estimula a caça e representa um problema ambiental mundialmente reconhecido. Outros fatores, a exemplo da agricultura de corte e queima e a contínua remoção da vegetação para a criação de bovinos e caprinos, contribuem para o empobrecimento ambiental da região. As descrições dos mamíferos de caça registrados no artigo foram baseadas em amostras de coleções científicas, além de dados disponíveis na literatura. Os pesquisadores visitaram as coleções de mamíferos da Universidade Federal da Paraíba (UFPB), Universidade Federal de Pernambuco (UFPE), Museu Nacional da Universidade Federal do Rio de Janeiro (UFRJ), e o Museu de Zoologia da Universidade de São Paulo (MZUSP). O catálogo pode ser acessado no endereço http:// ethnobioconservation.com/index. php/ebc/article/view/90/79.

Giselle Soares 